\title{
Deformations of A Homogeneously Doped Al-ZnO Cantilever Using Ideal Wurtzite Crystal Structure
}

\author{
Md Rabiul Awal ${ }^{1}$, Muzammil Jusoh ${ }^{2}$, Shakir Saat ${ }^{3}$, Muhammad Syarifuddin Yahya ${ }^{1}$, \\ Md. Nurul Islam Siddique ${ }^{1}$, Mohd Zaki Mohd Yusoff ${ }^{4}$ \\ ${ }^{1}$ Faculty of Ocean Engineering, Technology and Informatics, Universiti Malaysia Terengganu (UMT), \\ 21030 Kuala Terengganu, Terengganu Darul Iman, Malaysia, \\ rabiulawal1@gmail.com, \{syarif_yahya; m.nurul\}@umt.edu.my \\ ${ }^{2}$ BioEM, School of Computer and Communication Engineering, Universiti Malaysia Perlis (UniMAP), \\ KampusPauh Putra, 02600, Arau, Perlis, Malaysia, muzammil@unimap.edu.my \\ ${ }^{3}$ Faculty of Electronics and Computer Engineering, Universiti Teknikal Malaysia Melaka (UTeM), \\ Jalan Hang Tuah Jaya, 76100 Durian Tunggal, Melaka, Malaysia, shakir@utem.edu.my \\ ${ }^{4}$ Department of Applied Sciences, Universiti Teknologi MARA (UiTM) CawanganPulau Pinang, \\ Jalan PermatangPauh, 13500 PermatangPauh, Pulau Pinang, Malaysia, zaki7231@uitm.edu.my
}

\begin{abstract}
A methodology to calculate the deformation of crystal structure is presented in this paper. $\mathrm{Al}$ doped $\mathrm{ZnO}$ is used to form the acoustic cantilever in ideal wurtzite crystal structure. The expansion of the applied cantilever is calculated by the proposed methodology and presented accordingly. In addition, the validation of the proposed method is attached with significant trade-offs with the classical theory of displacements.
\end{abstract}

Key words: Acoustic cantilever, $\mathrm{Al}$ doped $\mathrm{ZnO}$, Wurtzite crystal

\section{INTRODUCTION}

Recently, acoustic energy transfer (AET) technology has drawn significant industrial attention. Eventually, AET possesses wide range of applications, including, portable electronic device charging, implantable devices powering and more [1]. Specially, where the presence of electromagnetic radiation is not appreciated, AET can perform within the safety margin by far.

Several types of techniques are available to perform AET including plate, diaphragm or cantilever structured transmitter and receiver. Among them, cantilever approach to propagate acoustic energy is particularly adventitious using multilayer formation. In this format, multiple materials are used in multiple layers to con $\mathrm{rm}$ the device structure. Several materials can be chosen for the cantilever formation. However, among them, zinc oxide $(\mathrm{ZnO})$ is one of the common materials to use.
To calculate the deformation of an acoustic cantilever, usually wave equations is preferable. However, these equations are complex, and parameter limited, yet difficult to understand [2]. Hence, we set our motivation to find a more generalized form of analysis.

In this paper, we proposed a set of approach to calculate the deformation of a cantilever. We have modeled the cantilever by two layer configuration, a piezoelectric (PZT) layer and a non-PZT or a base layer. The PZT layer is a deposited layer with $\mathrm{Al}$ doped $\mathrm{ZnO}$. The deposition is confirmed on the base layer which is a sliced silicon wafer. The ideal wurtzite crystal structure is considered for the deposition layer and applied for the device deformation and displacements calculation [3, 4].

The remainder of this paper is organized as follows; Section 2. presents details of the modeling of the proposal including the unit cell and unit block design. Section 3. calculates the direction of the device deformation. Section 4. discusses the deformations occurred in the associated air medium. Lastly, Section 5. and 6. conclude this paper with theoretical validation and some prospective future agendas.

\section{MODELING OF THE CANTILEVER}

Cantilever modeling depends on the determined dimensions in $\mathrm{x}, \mathrm{y}$ and $\mathrm{z}$ axes. These axes represent the cantilever length, width and thickness by $\mathrm{L}, \mathrm{W}$ and $\mathrm{t}$. respectively toward $\mathrm{x}, \mathrm{y}$ and $\mathrm{z}$ axis. Thickness of the cantilever depends on the deposition and base wafer layer. This given geometric dimensions represent the total volume of the cantilever as well. Hence, the number of atoms and unit cells in thatparticular configuration can be measured. Eventually, the cantilever displacements can be calculated by the number of atoms and unit cells within the deposition layer, using the device vibration as a context. 


\section{Conditions:}

We have applied the homogeneous doping method to dope $\mathrm{Al}$ in $\mathrm{ZnO}$. The doped unit cell is presented in $\mathrm{g}$. 1. We have considered the ideal crystal structure. That is, the crystal bonds follow the ideal crystal structure and the structure is strained to the standard crystal formula as in Figure 1. The deposited thin film is considered as polycrystalline with multiple crystal Si substrates. In brief, it is assumed that, the formed $\mathrm{Al}$ doped $\mathrm{ZnO}$ exhibits standard doped crystal behavior.

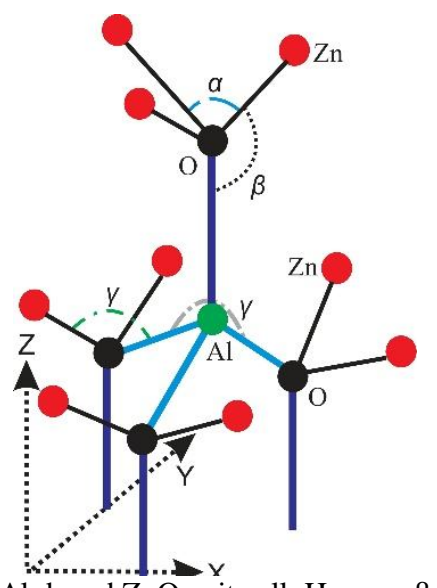

Figure 1: Al doped $\mathrm{ZnO}$ unit cell. Here, $\alpha=\beta=109.47^{0}$; $\gamma=141.06^{0} ; \mathrm{l}_{\mathrm{ZnO}}=1.9757 \AA ; 1_{\mathrm{AlO}}=1.8 \AA$.

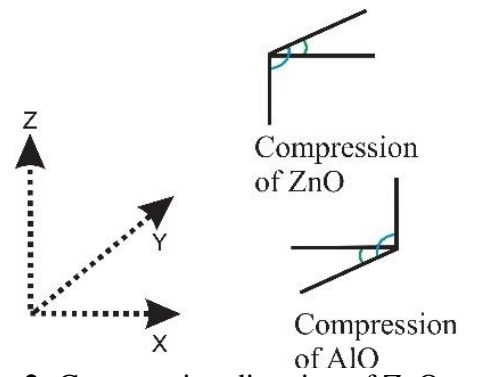

Figure 2: Compression direction of $\mathrm{ZnO}$ and $\mathrm{Al}$.

\subsection{Crystal unit cell modeling}

Unit cell of the crystal is compounded by zinc, oxygen and doped aluminum atoms. These atoms are connected by their assigned bonds. Hence, three types of bonds are available in the unit cells. Namely, $\mathrm{Al}-\mathrm{O}_{\text {vertical }}, \mathrm{Al}-\mathrm{O}_{\text {parallel }}, \mathrm{Zn}-\mathrm{O}$ [5]. The considered unit cell with the atomic description is presented in Figure 1.

Number of unit cells can be found by applying the deposition length and thickness as follows,

$\lceil N\rceil=\left\lceil N_{\text {cell }}^{\rightarrow x, z}\right\rceil=\left\lceil\frac{L^{\rightarrow x}}{L_{u}^{\rightarrow x}}\right\rceil \times\left\lceil\frac{t^{\rightarrow z}}{h_{u}^{\rightarrow z}}\right\rceil$

Where, $\mathrm{N}$ is the total number of cells in the deposition layer, $N_{\text {cell }}^{\rightarrow x, z}$ is the cells in $\mathrm{x}$ and z axis. $L_{u}^{x}$ and $h_{u}^{z}$ are the length and height of a unit cell which are defined as,

$$
\begin{aligned}
& L_{u}^{\rightarrow x}=2 \sqrt{\mathrm{ZnO}_{s}^{2}+\mathrm{AlO}_{s}^{2}-2 \mathrm{ZnO}_{s} \mathrm{AlO}_{s} \cos \gamma} \\
& h_{u}^{z}=d l_{Z n O}+l_{A l O}+d l_{A l O} \\
& =l_{Z n O} * \sin (\alpha-90)+l_{A l O}\{1 \\
& +\sin (\beta-90)\}
\end{aligned}
$$

Here,

$Z n O_{s}=\sqrt{l_{Z n O}^{2}-\left\{l_{Z n O} * \sin (\alpha-90)\right\}}$

And,

$A l O_{S}=\sqrt{l_{A l O}^{2}-\left\{l_{A l O} * \sin (\alpha-90)\right\}}$

Here, $\mathrm{L}$ and $\mathrm{t}$ are the deposition layers length and thickness. $\alpha, \beta$ and $\gamma$ are the angles produced by $\mathrm{Zn}-\mathrm{O}, \mathrm{Al}-\mathrm{O}$ and $\mathrm{Zn}-\mathrm{Al}$ bond. $l_{\mathrm{ZnO}}$ and $l_{A l O}$ define the bond length and $\mathrm{ZnO}_{S}, \mathrm{AlO}_{\mathrm{s}}$ are the produced slopes by the bond.

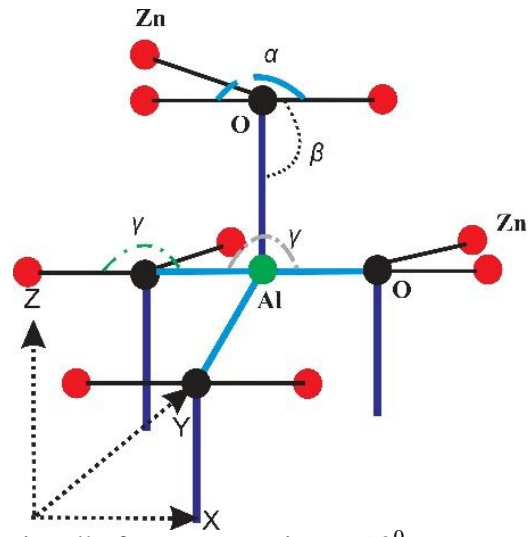

Figure 3: Unit cell after compression at $90^{\circ}$. Here, $\alpha=180^{\circ} ; \beta=90^{\circ}$; $\gamma=180^{\circ} ; 1_{\mathrm{ZnO}}=1.9757 \AA ; 1_{\mathrm{AlO}}=1.8 \AA$.

\subsection{Angles between the bonds}

In this particular measurement, we have applied the ideal wurtzite crystal structure. The angle between the bonds (i.e. $\mathrm{Zn}-\mathrm{O}, \mathrm{Al}-\mathrm{O})$ are considered as $109.47^{0}$ in this structure. Hence, the maximum deformation of the cantilever will occur at the angles of $90^{\circ}$ and $180^{\circ}$ respect to the $\mathrm{z}$ axis for thickness vibration mode. So the maximum displacement will occur at deformation angles of $19.47^{\circ}$ and $-70.53^{\circ}$.

Angles between the bonds can be identified according to the applied stress. Hence, the difference between the initial angle under free stress and deformed angle under an applied stress. However, under stress, bond angles can be categorized as angle of deformation and exact angle for maximum deformation. This exact angle will produce the highest device displacement in a particular direction. For example, angle $\beta$, which is the angle between $\mathrm{Zn}-\mathrm{O}$ and $\mathrm{Al}-\mathrm{O}$ bond, has the initial value of $109.47^{0}$. However, when a stress is applied, this angle starts to decrease. At an angle of $0^{0}$ the bonds overlap each other in parallel fashion. Eventually, the bonds are perpendicular to each other at $90^{\circ}$. This condition results the maximum deformation to the $\mathrm{x}$ and $\mathrm{y}$ axes in the thickness vibration mode. 


\subsection{Compression to the z-axis of unit cell}

The compression of a unit cell in a particular axis will cause an absolute expansion in correlated axes. As depicted in figure 3 , the bond angles are stretched due to the expansion of the unit cell. This expansion of a unit cell to the $\mathrm{z}$ axis can be calculated as,

$\left|C^{\rightarrow Z}\right|=\sum_{K=1}^{N \rightarrow z}\left(C_{Z n O}^{\rightarrow z}+C_{A l O}^{\rightarrow z}\right)_{k}$

Where,

$C_{Z n O}^{\rightarrow Z}=\sqrt{l_{Z n O}^{2}+l_{Z n O_{s}}^{2}-2 l_{Z n o} l_{Z n O_{s}} \cos (\alpha-90)}$

$C_{A l O}^{\rightarrow Z}=\sqrt{l_{A l O}^{2}+l_{A l O_{S}}^{2}-2 l_{A l O} l_{A l O_{S}} \cos (\beta-90)}$

The compression of a unit cell is presented in Figure 4. From the figure, it is clear that, the compression of the unit is the minimum at $90^{\circ}$ compression angle. We have considered the absolute value for the compression when the angle is less than $90^{\circ}$. In addition, Figure. 5 presents the relation of cumulative compression to the deposition thickness. It is evident from the figure that, the thicker deposition will result larger cumulative compression.

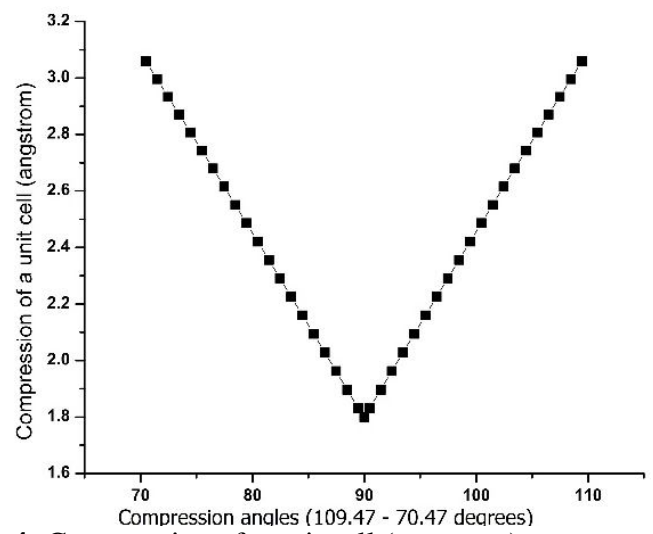

Figure 4: Compression of a unit cell (angstrom) vs compression angles (109.47 - 70.47 degrees)

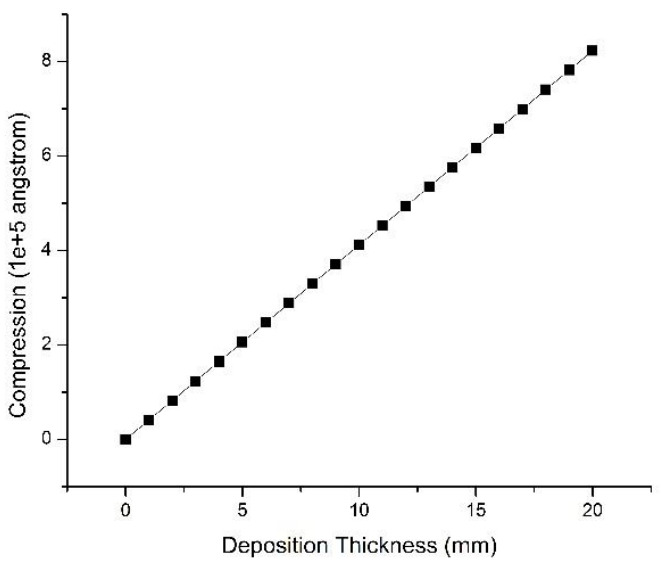

Figure 5: Cell compression towards the deposition thickness

\subsection{Expansion to the $x$ axis of unit cell}

The expansion of a Unit cell respect to the $\mathrm{x}$ axis can be described as,

$E^{\rightarrow x, y}=\sum_{l=1}^{N^{\rightarrow x}} 2\left(\left|E_{Z n O}^{\rightarrow x, y}\right|+\left|E_{A l O}^{\rightarrow x, y}\right|\right)_{l}$

Where,

$E_{Z n O}^{\rightarrow x, y}=E_{A l O}^{\rightarrow x, y}=E_{Z n A l}^{\rightarrow x, y}=\sqrt{l_{Z n O}^{2}+l_{A l O}^{2}-2 l_{Z n o} l_{A l O} \cos \gamma}$

Which requires the following condition to be satisfied for the maximum deformation,

$\exists ! E_{\max }^{\rightarrow x, y}=\prod_{k=1}^{n=110} \alpha_{k} \Lambda \beta_{k} ;\left(0<\alpha_{k}, \beta_{k}<109.47\right)$

Unit cell expansion is presented in Figure. 6. Expansion of unit cells will reach maximum value when thecompression angle is $90^{\circ}$. That is, unit expansion ismaximum when the horizontal bonds are exactly perpendicular to the vertical bonds. However, the cumulative expansion will increase linearly according to the deposition length. It is depicted in Figure 7.

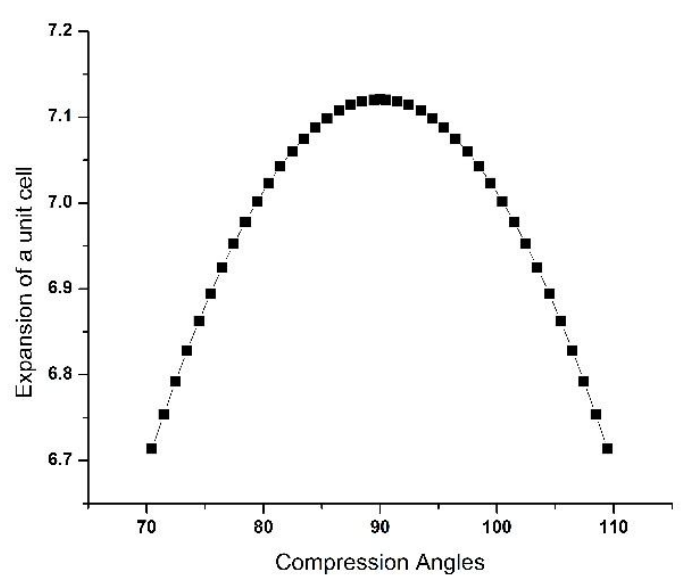

Figure 6: Expansion of a unit cell (angstrom) vs Compression Angles (109.47 - 70.47 degrees) 


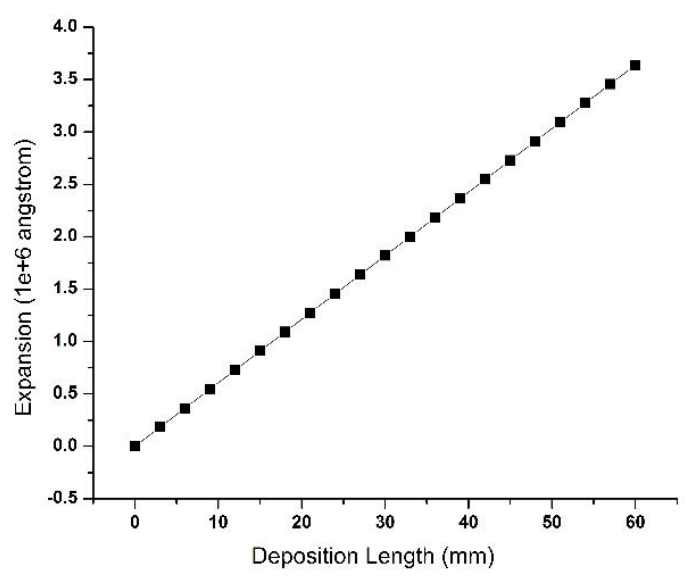

Figure 7: Deposition length vs expansion of the cantilever

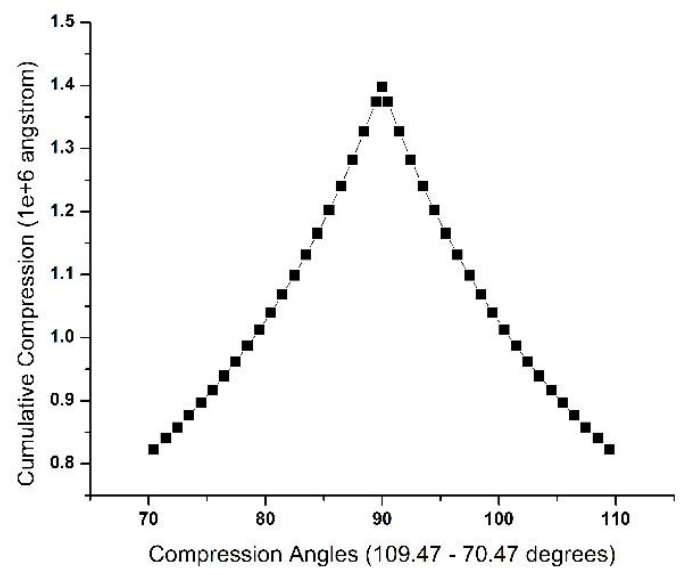

Figure 8: Unit cell deformation (compression) towards cantilever length

Similar to unit cell expansion, unit cell compression also presents pick value when thecompression angle is $90^{\circ}$.However, the minimum value can be obtained when the angles are $70^{\circ}$ and $109.47^{\circ}$, as in Figure 8.

\section{DIRECTION OF DEFORMATION}

In order to measure the deformation direction of the cantilever, we must determine two initial parameters. Firstly, the deformation in the deposited unit cell and then the associated silicon wafer unit. To do so, the mass of the unit cell and wafer area need to be confirmed.

\subsection{Unit cell mass}

The unit cell mass of the deposited area can be measured by calculating the mass of the atoms within the cell. Here, we have considered, one $\mathrm{Al}$, four $\mathrm{O}$ and twelve $\mathrm{Zn}$ atoms to format the unit cell. Hence, the unit cell consisting of seventeen atoms, which gives total molar mass of 875.539138 $\mathrm{g} / \mathrm{mol}$. To calculate the mass,

$W_{\text {unit cell }}=\sum_{k=1}^{l} A L_{k}+\sum_{k=1}^{m} O_{k}+\sum_{k=1}^{n} Z n_{k}$

Here, $1, \mathrm{~m}$ and $\mathrm{n}$ represent the total number of $\mathrm{Al}, \mathrm{O}$ and $\mathrm{Zn}$ atoms in the unit cell. To be noted here, the unit of $W_{\text {unit cell }}$ is $\mathrm{g} / \mathrm{mol}$. To present in $\mathrm{kg}$, we need to multiply with the conversion factor as,

$W_{\text {unit cell }}=\sum_{k=1}^{l} A L_{k}+\sum_{k=1}^{m} O_{k}+\sum_{k=1}^{n} Z n_{k} \times 1.66 e-27$

The mass of the unit cell is presented in table 1. We have considered a silicon wafer to perform the deposition (root disk diameter 2-inch, thickness $0.525 \mathrm{~mm}$, weight $10 \mathrm{~g}$ ). A slice of $60 \mathrm{~mm} \times 10 \mathrm{~mm}$ is selected as the base layer for material deposition. We have considered an extremely thin slice, thickness of $10 \AA$. The details are given in table 2 .

Table 1: Unit cell mass of the deposited $\mathrm{Al}-\mathrm{ZnO}$

\begin{tabular}{|c|c|c|}
\hline Compound Materials & Weight $\mathbf{( g / m o l})$ & \# of atoms \\
\hline $\mathrm{Al}$ & 26.981538 & 1 \\
\hline $\mathrm{Zn}$ & 784.56 & 12 \\
\hline $\mathrm{O}$ & 63.9976 & 4 \\
\hline Total Cell Mass & 875.539138 & 17 \\
\hline Converted Cell mass & $\begin{array}{c}1.45386692 \mathrm{e}-24 \\
\mathrm{~kg}\end{array}$ & 17 \\
\hline
\end{tabular}

Table 2: Cantilever dimension descriptions

\begin{tabular}{|c|c|}
\hline Cantilever Layers & Descriptions \\
\hline \multicolumn{2}{|c|}{ PZT Layer } \\
\hline Materials & $\mathrm{Al}$ doped $\mathrm{ZnO}$ \\
\hline Length & $60 \mathrm{~mm}$ \\
\hline Width & $10 \mathrm{~mm}$ \\
\hline Thickness & $20 \mathrm{um}$ \\
\hline Volume & $12 \mathrm{~mm}$ \\
\hline Non-PZT Layer \\
\hline Length & $60 \mathrm{~mm}$ \\
\hline Width & $10 \mathrm{~mm}$ \\
\hline Thickness & $10 \AA$ \\
\hline Volume & $6 \mathrm{e}-4 \mathrm{~mm}$ \\
\hline
\end{tabular}

\subsection{Associated silicon wafer base block mass}

We have considered a silicon wafer to perform the deposition (root disk diameter 2-inch, thickness $0.525 \mathrm{~mm}$, weight $10 \mathrm{~g}$ ). A slice of $60 \mathrm{~mm} \times 10 \mathrm{~mm}$ is selected as the base layer for material deposition. We have considered an extremely thin slice, thickness of $10^{-}$The details are given in table 2 .

The mass of the associated silicon wafer block with the unit cell can be measured as, 
$W_{\text {Unit }}=\frac{W_{\text {Total }}}{N_{\text {cell }}^{\rightarrow x}}$

Here, $W_{\text {Unit }}$ is the mass of the unit block, $W_{\text {Total }}$ is the total mass of the block and $N_{\text {cell }}^{\rightarrow x}$ is the total number of unit cells in x axis.

\subsection{Resultant force of the unit cell}

The force induced by a unit cell can be defined by the classical force law as follows,

$F_{\text {cell }}^{\rightarrow x}=m_{a}^{\rightarrow x}=m \frac{E^{\rightarrow x}}{(1 / f)}$

Here, $\mathrm{m}$ is the mass and $\mathrm{E}$ is the expansion toward $\mathrm{x}$ axis of the unit cell and $f$ denotes the operating frequency.However, the silicon wafer block is impacted by the gravitational pull only, as it is a non-PZT. The angle between the aforementioned two forces is considered to be $90^{\circ}$. Hence, the resultant force of the unit cell from the two associated forces is given by,

$F_{R}^{\rightarrow x, y, z}=\sqrt{{F_{\text {cell }}^{\rightarrow x^{2}}+F_{\text {wafer }}^{\rightarrow-z}}^{2}}$

Here, $F_{\text {wafer }}$ presents the gravitational pull acting on the particular area beneath the deposited unit cell of the base silicon wafer. Hence, the total deformations collected from all the unit cells of the device can be expressed as,

$F_{R_{\text {Total }}}^{\rightarrow x, y, z}=\sum_{j=1}^{N_{\text {cell }}^{\rightarrow x}} F_{R_{j}}^{\rightarrow x, y, z}$

Here, $F_{R_{\text {Total }}}$ presents the cumulative deformations of the unit cells to the $\mathrm{x}$ axis. In relation, this value actually measures the tip displacements of the cantilever.Therefore, the displacements,

$|d|^{\rightarrow x, z}=\left\lceil\sum_{j=1}^{N_{\text {cell }}^{\rightarrow x}} F_{R_{j}}^{\rightarrow x, y, z}\right\rceil$

It is worth to note that, the direction of the deformationcompletely depends on the direction of the applied force. However, it cannot exceed the bond angles of the crystal structure.

Table 3: Cantilever dimension and deformation descriptions

\begin{tabular}{|c|c|c|c|}
\hline Cantilever & $\begin{array}{c}\text { Deposited } \\
\text { layer } \\
\text { thickness }\end{array}$ & $\begin{array}{c}\text { Unit cell } \\
\text { deformation } \\
\text { (axis) }\end{array}$ & $\begin{array}{c}\text { Total } \\
\text { deformation } \\
\text { (axis) }\end{array}$ \\
\hline To length & $10 \AA$ & $0.4072 \AA(\mathrm{x})$ & $\begin{array}{c}3.6391 \mathrm{e}+6 \\
\AA\end{array}$ \\
\hline $\begin{array}{c}\text { To } \\
\text { thickness }\end{array}$ & $10 \AA$ & $1.2585 \AA(\mathrm{z})$ & $\begin{array}{c}8.2295 \mathrm{e}+5 \\
\AA\end{array}$ \\
\hline
\end{tabular}

\section{DEFORMATIONS OF THE ACOUSTIC MEDIUM}

The displacements of the cantilever cause the related air to be deformed to the direction of the displacement. This deformation depends on the cantilever dimension, displacement amplitude and operating frequency. The air deformation can be measured by the continuous wave equation. However, as we know the displacement pro le of the cantilever, the collision theory for two objects can also be applied. The force induced by the cantilever displacements,

$F_{1}^{\rightarrow x, y, z}=W^{\rightarrow x, y, z} \times d^{\rightarrow x, z}$

Where,

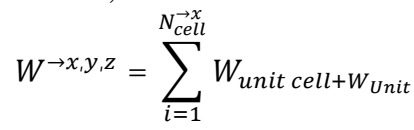

The deformation results are presented in table 3 .

\section{CONCLUSION}

A geometric approach is proposed in this paper to calculate the deformation from a doped crystal structure. $\mathrm{Al}$ doped $\mathrm{ZnO}$ is applied for the crystal configuration. By applying the proposed structure, we have calculated the deformation of the $\mathrm{Al}$ doped $\mathrm{ZnO}$ cantilever. It is found that, the cantilever can be expanded up to $3.6391 \mathrm{e}+6 \AA$ in length to $\mathrm{x}$-axis with the unit cell expansion of $0.4072 \AA$.

\section{ACKNOWLEDGEMENT}

This work is partly supported by Universiti Malaysia Terengganu, under fundamental research grant scheme (FRGS 59604), Ministry of Higher Education , Government of Malaysia.

\section{REFERENCES}

1. M. R. Awal, M. Jusoh, T. Sabapathy, M. Kamarudin, \&R. A. Rahim. State-of-the-art developments of acoustic energy transfer. International Journal of Antennas and Propagation, 2016.

2. K. M. Holford. Current practice and applica-tions of acoustic emission. Experimental Analysis of Nano and Engineering Materials and Structures. pp. 927-928, 2007.

3. T. H. Yao, Soon-KU. Oxide and nitride semi-conductors: Processing, properties, and applications. Springer Science \& Business Media, 2009. ISBN 978-3-540-88846-8.

4. H. Morkoc, Ü. özgur. Zinc Oxide: Fundamentals, Materials and Device Technology. Wiley-Interscience, 2009. ISBN 978-3-527-40813-9.

5. F. A. Maldonado, A. Stashans. Al-dopedZnO: Electronic, electrical and structural proper-ties. Journal of Physics and Chemistry of Solids.2010, vol. 71, issue. 5, pp. 784-787, 2010.

6. X. Li, W. Y. Shih, I. A. Aksay, \& W. H.Shih. Electromechanical

Behavior 
Md Rabiul Awal et al., International Journal of Advanced Trends in Computer Science and Engineering, 9(4), July - August 2020,5406 - 5410

PZT-BrassUnimorphs. Journal of the American Ceramic Society, vol. 82, issue. 7, pp. 1733-1740, 1999. 